\title{
COMUNICAÇÃO ORGANIZACIONAL NA ERA DIGITAL: ANÁLISE DE CANAIS NO YOUTUBE EM HOSPITAIS QUE ATENDEM PACIENTES COM CÂNCER
}

Amanda Sueli Alves Albuquerque Amaral, Karine de Andrade Silva, Maicon Ferreira Santana Pinto de Lana, Thaisa Sallum Bacco, Victor Gomes Barbosa, William Asaph Yanraphel da Silva Souza

Universidade do Oeste Paulista - Unoeste, Curso de Comunicação Social, Presidente Prudente, SP. E-mail: amandasamaral@live.com

\section{RESUMO}

Há 20 anos, quando se buscava o significado de algo desconhecido, recorria-se ao dicionário. Com o surgimento da internet, as plataformas de busca tornaram-se o meio mais rápido e utilizado para sanar dúvidas e adquirir conhecimento. Em sentido proporcional, novas plataformas surgiram e a comunicação se desenvolveu. Considerando esse cenário, o presente artigo teve como objetivo geral refletir quais são as ferramentas jornalísticas utilizadas atualmente para trabalhar os valores de uma organização na área da saúde. A metodologia aplicada teve como abordagem a pesquisa qualitativa do tipo exploratória. Os procedimentos adotados para o levantamento e coleta de dados foram a pesquisa bibliográfica e pesquisa de campo. Para a coleta de dados, foi feita a observação de canais no YouTube de instituições que oferecem tratamento contra o câncer. Por meio das observações coletadas e da análise triangulada dos dados, foram analisadas as bases teóricas da comunicação organizacional e o uso do YouTube como ferramenta corporativa para hospitais que oferecem atendimento oncológico.

Palavras-chave: comunicação organizacional; ferramentas jornalísticas; jornalismo organizacional; YouTube.

\section{ORGANIZATIONAL COMMUNICATION IN THE DIGITAL AGE: YOUTUBE CHANNEL ANALYSIS AT HOSPITALS} SERVING CANCER PATIENTS

\begin{abstract}
Twenty years ago, when one sought the meaning of something unknown, one went to the dictionary. With the emergence of the internet, search platforms have become the fastest and most used means of healing doubts and acquiring knowledge. Proportionally, new platforms emerged and communication developed. Considering this scenario, the present article had as general objective to reflect which are the journalistic tools currently used to work the values of an organization in the health area. The methodology applied was qualitative research of the exploratory type. The procedures adopted for the collection and collection of data were bibliographic research and field research. For the collection of data, it was made the observation of channels on YouTube of institutions that offer treatment against cancer. Through the observations collected and the triangulated data analysis, the theoretical bases of organizational communication and the use of YouTube as a corporate tool for hospitals offering oncological care were analyzed.

Keywords: organizational communication; journalistic tools; organizational journalism; YouTube.
\end{abstract}

\section{INTRODUÇÃO}

Para compreender a Comunicação Organizacional na Era Digital e quais são as ferramentas estratégicas para se trabalhar a imagem, identidade e reputação de uma organização, é necessário, de antemão, entender que não se trata de uma área nova, visto que seus fundamentos continuam os mesmos. $O$ novo panorama das organizações deu-se com o advento da internet, que implicou no uso de novas ferramentas comunicacionais à disposição da organização. $\mathrm{Na}$ área jornalística não foi diferente; atualmente, além dos canais analógicos de comunicação, os jornalistas também podem se apropriar dos canais digitais que se prestam aos objetivos de uma 
organização.

Dessa maneira, o presente artigo debruçou-se nos conceitos na área de Comunicação Organizacional, estudando suas formas, seus públicos e as ferramentas disponíveis para atingir os públicos de interesse de maneira segmentada.

A escolha por trabalhar a área da saúde se deu pelo novo perfil de paciente que chega até os consultórios médicos: não se trata mais de uma relação em que o médico é o único receptor da mensagem; pacientes, com canais de busca online, já sabem seu diagnóstico, formas de tratamento e quais são as implicações. Por isso, a informação sobre saúde na internet vem crescendo cada vez mais e, boa parte delas, provém de organizações da mesma área. $E$ por onde grande parte dessas informações são consumidas?

Outro aspecto a ser considerado é que tais informações disponíveis no contexto do ciberespaço apresentam-se no formato audiovisual.

Assim, essa pesquisa se debruçou em refletir quais são as ferramentas jornalísticas utilizadas atualmente para trabalhar os valores de uma organização na área da saúde, sobretudo, o uso do YouTube em organizações como o Hospital Israelita Albert Einstein e o A. C. Camargo Cancer Center, locais onde a pesquisa de campo foi realizada.

Partindo desses questionamentos, a pergunta-síntese desse artigo foi assim delineada: como trabalhar os valores de instituições de saúde que oferecem tratamento oncológico, com produções jornalísticas voltadas para o YouTube enquanto ferramenta corporativa?

\section{METODOLOGIA}

Diante do objetivo desta investigação, que é refletir sobre a produção de conteúdo jornalístico para um canal no YouTube, a abordagem escolhida quanto à natureza da pesquisa foi a qualitativa, pois se trata da compreensão de algo subjetivo, sem estar baseado em dados estatísticos. Quanto ao tipo da abordagem qualitativa, foi escolhida a exploratória, pois o objetivo da pesquisa é norteado em trabalhar um tema pouco explorado.

Em relação aos procedimentos adotados para o levantamento e coleta de dados, foram utilizadas a documentação direta e indireta. A documentação indireta foi realizada por meio da pesquisa bibliográfica na área de Comunicação Organizacional com ênfase no Jornalismo Organizacional.

Após o levantamento de dados feitos pela documentação indireta, percebeu-se a necessidade de um procedimento que agregasse mais informações sobre essa área pouco explorada. Então, os pesquisadores levantaram as informações por meio da documentação direta, utilizando os procedimentos: pesquisa de campo e observação direta dos canais no YouTube de instituições que oferecem tratamento contra o câncer.

Os objetos de estudos escolhidos para esse artigo foram os canais no YouTube do Hospital Israelita Albert Einstein e do A.C. Camargo Cancer Center, instituições onde os pesquisadores realizaram pesquisa de campo no primeiro semestre de 2018. A escolha dos objetos de estudo se deu após a análise do conteúdo de 66 canais no YouTube de hospitais oncológicos.

Após o levantamento e a coleta dos dados, foi necessária a triangulação dos dados obtidos. Isso significa que todos os dados foram transcritos, avaliados, separados em categorias de análise, interpretados e cruzados para responder à pergunta-síntese do artigo.

\section{RESULTADOS}

Conforme a realização do levantamento bibliográfico, análise das instituições de saúde que oferecem atendimento oncológico e a pesquisa de campo no Hospital Israelita Albert Einstein e no A.C Camargo Cancer Center, constatou-se que o YouTube como ferramenta do jornalismo organizacional é uma área pouco explorada. Dos 66 canais analisados, somente seis (12\%) trabalham exclusivamente com conteúdo voltado à informação.

Partindo de um critério mais amplo, foi realizada a análise utilizando um segundo viés, quanto aos conteúdos divulgados pelos canais: a) somente conteúdo institucional; b) somente conteúdo informativo; c) somente clipping; d) clipping e conteúdo informativo; e) clipping e conteúdo institucional; f) conteúdo informativo e conteúdo institucional; g) clipping, conteúdo informativo e conteúdo institucional. Segundo os dados coletados pelos pesquisadores, a partir da observação direta dos sites realizada em março de 2018, o conteúdo com maior divulgação é o institucional, estando presente em 26 dos 66 canais analisados. 
Considerando o cenário das produções audiovisuais no YouTube veiculadas por hospitais que oferecem atendimento oncológico, foi necessário traçar um paralelo com a bibliografia da área de Comunicação Organizacional para entender o que mudou. A partir da pesquisa, constatou-se que as bases da Comunicação Organizacional ainda se mantêm as mesmas, visto que o conceito continua o mesmo. $O$ que se alteraram foram as ferramentas utilizadas para ativar a comunicação dentro das organizações.

Em relação às instituições da área da saúde, comprovou-se que, quando se trata de conteúdo a ser veiculado, a informação do paciente aparece como fator primordial na área do Jornalismo Organizacional, visto que, em uma das instituições visitadas na pesquisa de campo, o Hospital Israelita Albert Einstein, a premissa das ações de comunicação consiste em "informação do paciente". Além disso, observou-se a necessidade de um Departamento de Comunicação estruturado com profissionais de todas as áreas para que a estratégia seja eficaz e bem executada.

\section{DISCUSSÃO}

Por meio dos dados levantados, a presente pesquisa problematizou o porquê de existirem poucos vídeos voltados à informação nesse cenário do uso do YouTube como ferramenta corporativa e, também, no uso da plataforma para atingir os públicos de interesse das instituições. Assim, buscou-se, de antemão, o conceito de comunicação. Torquato (2008) entende que a comunicação está relacionada com o desenvolvimento econômico, social e político. $O$ autor explica que no final da década de 1960 e, com os processos de industrialização cada vez mais latentes, as empresas tomaram ciência da importância do relacionamento com seus públicos de interesse. Entretanto, mesmo com esse insight, os recursos para o investimento na área da comunicação eram rasos, prejudicando ações de comunicação interna e externa das organizações para/com seus públicos. A partir da entrada das multinacionais, os modelos foram reestruturados e sofisticados, contribuindo para a evolução da comunicação. (TORQUATO, 2008).

As organizações só puderam adotar um posicionamento estratégico com o fim da
Ditadura Militar ${ }^{1}$, visto que o controle sobre a comunicação era constante e feito de forma desmedida por profissionais da área de Recursos Humanos. Com a mudança do posicionamento das organizações, a comunicação transformou-se em ferramenta para que as relações entre o público interno e externo fossem aprimoradas e fomentadas, trabalhando suas formas que se subdividem em: comunicação cultural, comunicação administrativa, sistemas de informação e comunicação social. As três primeiras existem por si só, enquanto a última, precisa ser ativada.

Torquato (2008) explica que a comunicação cultural pode ser definida como o clima interno das organizações. Já a comunicação administrativa pode ser entendida como aquela que parte em um fluxo descendente, dos gestores da organização, como cartas internas e regulamentos. O terceiro tipo de comunicação, os sistemas de informação, abarcam todas as informações armazenadas em banco de dados.

Partindo do pressuposto de que as formas de comunicação explicadas acima são inerentes à organização, há de entender o porquê de a comunicação social precisar ser ativada. Com todas essas formas de comunicação - cultural, administrativa e sistemas de informação - acontecendo sem mediação e instantaneamente, os ruídos são frequentes. A comunicação social utiliza das áreas de Relações Públicas, Jornalismo, Marketing e Publicidade Propaganda para administrar estrategicamente os fluxos de comunicação da organização.

Todas essas áreas devem trabalhar para alinhar a identidade, a imagem e a reputação organizacional.

Aspectos como o alinhamento dos funcionários com a organização, cobertura da mídia e as mensagens corporativas produzidas e veiculadas são trabalhadas com os públicos internos e externos de uma organização, por meio das duas primeiras colunas da comunicação social: comunicação interna e externa.

Segundo Torquato (2008, p. 54), a missão básica da comunicação interna consiste em "[...] contribuir para o desenvolvimento e a manutenção de um clima positivo, propício ao cumprimento das metas estratégicas da

\footnotetext{
${ }^{1}$ Período da política brasileira em que os militares governaram o Brasil. Esta época vai de 1964 a 1985. Caracterizou-se pela falta de democracia, supressão de direitos constitucionais, censura, perseguição política e repressão aos que eram contra o regime militar.
} 
organização e ao crescimento continuado de suas atividades e serviços e à expansão de suas linhas e produtos". $O$ autor também segmenta os canais de comunicação internos em: jornais e revistas; boletins, folhetos, memorandos e comunicados; quadro de avisos e murais; reuniões grupais e encontros; conversas individuais com funcionários; programas de "portas abertas", caixas de sugestões e fluxo ascendente; programas de promoção profissionais.

Já a comunicação externa tem valor estratégico, pois, conforme afirma Torquato (2008, p. 61), “[...] é responsável pelo posicionamento e pela imagem da organização da sociedade". Além disso, o autor afirma que o público externo é composto pelos formadores de opinião, ou seja, a própria opinião pública.

Entretanto, há de entender que, atualmente, com a tecnologia da informação e os novos canais oferecidos na internet, não é apenas a assessoria de imprensa que atua para atingir a opinião pública. Os canais de mídias sociais também se fazem canais externos de comunicação.

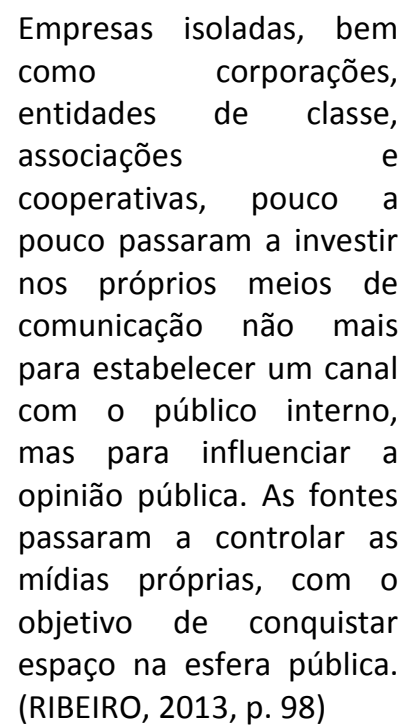

O controle das mídias pelas fontes fez nascer um novo sistema dentro das organizações, as chamadas mídias das fontes, que demonstram o novo papel das organizações que anteriormente eram limitadas somente a serem as detentoras das informações.

Desta forma, a imprensa tradicionalmente vista como um expectador externo aos fatos começa a perder a totalidade do domínio da cena informativa. A opinião pública passa a contar com

$$
\begin{aligned}
& \text { informações coletadas, } \\
& \text { selecionadas, tratadas } \\
& \text { editorialmente, filtradas e } \\
& \text { difundidas por entidades } \\
& \text { ou movimentos sociais, ou } \\
& \text { sejar corporações } \\
& \text { detentoras de interesses } \\
& \text { corporativos. } \\
& \text { (SANT'ANNA, 2006, p. 3) }
\end{aligned}
$$

Nesse contexto, Ribeiro (2013, p. 99) afirma que "[...] as mídias das fontes podem ser instrumentos corporativos de comunicação com alcance e influência suficientes para marcar território no ambiente midiático e agendar os debates políticos". Ou seja, para ele, o processo de transmissão da informação partindo diretamente das organizações deve entender a notícia como algo de interesse público e não somente aliados aos interesses da organização.

Assim, compreendeu-se que todos os canais das mídias sociais se prestam aos objetivos e metas de uma organização. Entretanto, é preciso saber que tipo de mensagem a empresa quer adotar para cada tipo de canal. Em relação ao uso da informação como forma de reforçar os valores de uma organização, discute-se a necessidade de as instituições reconhecem o valor do jornalismo para ativar a memória do público de interesse, prestando serviços e agregando valor e reputação àquelas organizações que atingem a opinião pública por meio do conteúdo informativo.

\section{CONCLUSÃO}

A internet revolucionou a forma de consumir informações e, também, de produzi-las. No ambiente organizacional, isso também se alterou. As organizações não se limitam somente em oferecer conteúdo como fontes para a grande imprensa, mas, sim, se projetam na sociedade por meio dos seus próprios meios de comunicação, atingindo a opinião pública. Assim, esses novos meios digitais interferem na estratégia organizacional e atuam como ferramentas para construir, reforçar ou modificar os valores da organização.

No cenário das instituições de saúde, a pesquisa de campo constatou que, quando uma instituição trabalha com a informação na plataforma online como ferramenta para construir a sua reputação, os resultados são positivos. É o caso do Hospital Israelita Albert Einstein, que possui como premissa a informação sobre saúde e, atualmente, valida as informações sobre o tema para o Google, a maior ferramenta 
de busca do mundo.

Ainda que a produção de conteúdo jornalístico para o YouTube seja incipiente, sabese que procurar adequar o código das mensagens para o meio no qual a sociedade está inserida, é uma importante estratégia de Comunicação Organizacional, principalmente na área da saúde, onde as instituições buscam passar autoridade no trato para/com seus pacientes.

\section{REFERÊNCIAS}

RIBEIRO, Â. A. Youtube, a nova TV corporativa: o vídeo na web como estratégia de comunicação pública e empresarial. Florianópolis: Combook, 2013. Disponível em: <iscom.com.br/wpcontent/uploads/Ebook_YouTube_Angelo_Ribeir o.pdf>. Acesso em: 22 jan. 2018.

SANT'ANNA, F. Mídia das fontes: o difusor do jornalismo corporativo. 2006. Disponível em: <http://www.bocc.ubi.pt/pag/santanna-

francisco-midia-fontes.pdf $>$. Acesso em: 15 maio 2018.

TORQUATO, G. Tratado de comunicação organizacional e política. São Paulo: Cengage Learning, 2008.

Recebido para publicação em 17/08/2018

Revisado em 30/08/2018

Aceito em 31/08/2018 